\title{
Repositioning, Reclaiming and Rejuvenating the Niche of Traditional Practitioners in the Face of Modernization in Selected African Countries
}

\author{
Prof. S. M Kang'ethe \\ University of Fort Hare, Department of Social Work and Social Development, \\ Box X1314, ALICE. 5700, South Africa \\ Email: skangethe@ufh.ac.za
}

\section{Doi:10.5901/mjss.2014.v5n27p1112}

\begin{abstract}
The aim of this article is, through a systematic review of literature, to elicit debate and discourse on advocating for the repositioning, reclaiming and rejuvenating the niche of traditional practitioners in societies. Findings indicate that traditional practitioners fill in important health and medical gaps; achieve important healing processes; constitute invaluable tasks such as facilitating children delivery; strengthen health and medical services through collaborative efforts and integration with modern biomedical practitioners. However, they are also retrogressive or perfidious in some instances when they carry out harmful tasks to people. The article recommends collaboration between the traditional practitioners and the modern biomedical practitioners; harmful practitioners to be discouraged societies; an examination of the pros and cons of the practitioners; traditional practitioners to be flexible, and accommodative of other current technologies and ideologies; Traditional practitioners to specialize and drop their versatile approach to treatment; Government to pass a bill providing for traditional practitioners licensing and control; and governments to offer goodwill to allow traditional practitioners growth and their integration with modern practitioners.
\end{abstract}

Keywords: Collaboration, integration, government goodwill, healers, Sangomas, wizards and witches, witchcraft

\section{Problem Statement}

It is this researcher's contention that some countries of the developing world still needs to reclaim, reposition, and rejuvenate the niche of traditional practitioners. This is because of the apparent positive role that these people have been associated with, are still capable of, and the need to fill some health gaps especially in the health sector. Although modernization, euro centrism, civilization and globalization continue to threaten their niche, this, according to this researcher's contention is wrong considering the health challenges that some African countries continue to grapple with. With the ratio of doctor/nurses: client ratio in most developing countries being unbelievably too low, with the services of child delivery experiencing congestion in hospitals, then the place of traditional practitioners such as traditional birth attendants and healers need to be reconsidered, reclaimed and rejuvenated. Perhaps working out a strong collaborative and integrative methodology to allow these practitioners to work in tandem with the modern health services is desirable. The fact that some empirical data suggests these services are culturally appropriate, people driven and effective further strengthens the need to evaluate and consider the pros and cons of these traditional practitioners (Kang'ethe, 2012; Mbuya, 2000).

\section{Background and Introduction}

Operationally, traditional practitioners are individuals with culturally defined powers, skills, especially treatment oriented ones, for example achieving the role of helping in child delivery, divining and foretelling the future, rain making and any other future predictive role (Kang'ethe, 2009). In general and without pinning who does what, these traditional practitioners are believed to have powers and capacities to interact with nature and tell people what is good for them, what to do at a particular event, how to avoid a bad catastrophe, how to protect oneself, how to make good fortune, etc. Many are believed to have spiritual connection with spiritual world and their work ordained and prescribed by the spirits of their ancestors/deities (King, Homsy \& Allen, 1992). They are believed to provide more power to individuals in order to handle social challenges, bring back lost love, facilitate economic might and power acquisition, enhance one's sexual libido, facilitate sexual pleasure giving processes such as penis enlargement, tightening of the vagina, etc. Therefore, these practitioners handle virtually all aspects that a complete individual would wish to accomplish. In many cases, their 
belief systems are embedded in both cultural and religious faiths. This has made the clients accessing their services usually follow them with deep religious and cultural conviction. This also makes following these practitioners a very intricate and a complex phenomenon. They therefore can control people's socio-emotional temperaments, and therefore act as a tool to shape individuals' souls, mind and the body (UNAIDS, 2000).

To be more precise, traditional practitioners includes but not restricted to the diviners (Sangomas), herbalists (traditional doctors), traditional birth attendants, wizards, witches, and spiritualists. While each of these practitioners are known differently in different geographical contexts, or have been performing different roles in a particular community, there is no clear role demarcation between any one of them, with some of them getting involved in an array of activities without any specialization. It has therefore been difficult for communities to identify, for example, a herbalist/ traditional doctor from a spiritualist, if the said herbalist/traditional doctor also does some acts that are spiritual in nature. For example, there are some herbalists who also divine using tools such as the divining boards, bones etc. These diviners are the ones commonly referred to as the Sangomas in most of the Southern African countries such as South Africa and Botswana (Kang'ethe \& Rhakudu, 2010; Mbuya 2000). There are some traditional doctors who are also believed to bring good or bad omens, making it difficult to distinguish their medical powers from spiritual powers. Many of these traditional practitioners, therefore, overlap in the execution of their tasks and services (Anderson \& Staugård, 1986; UNAIDS, 2000).

But despite the fact that these traditional practitioners continue to occupy a pivotal niche in their societies and to discharge culturally appropriate, people driven, and acceptable services (Kang'ethe, 2012; King, Homsy \& Allen, 1992), ironically some of their services and themselves also have been rendered redundant by the forces and imperatives of modernization, euro centrism and globalization (Kang'ethe, 2009; Anderson \& Staugård, 1986). However, the role of some of these practitioners will be laid to rest in the ensuing discussion as different kinds of these practitioners will form an important part of this researcher's discourse and debate of the traditional practitioners generally. However, this researcher is greatly interested in practitioners who have curative value like the herbalists and traditional healers; and also the traditional birth attendants.

This researcher who believes in tapping indigenous resources embedded in communities as an aspect of community development is of the conviction that Africans have let modernization, civilization, euro centrism, westernization, and globalization rob them of their culturally and indigenously ordained skills (Kang'ethe, 2011). The western based countries won to convince the Africans that their services were barbaric, naïve, unhygienic, and even dangerous for human consumption. Little did the Africans know that it was a schema by the western based countries to enlarge the market for their skills and services. And it is true because the services of the westerners are largely associated with modernization, civilization and today globalization. It is this researcher's contention that some of the services discarded by the Africans are services which if rejuvenated, repositioned and reclaimed could make a significant contribution to the development of most countries of the developing world (UNAIDS, 2000). This is why this researcher wants to elicit debates and discourses pertaining to relooking back at the values embedded in some of these traditional practitioners. This he agrees with the call by the World Health Organization (WHO, 2002) for countries of the developing world to consider their culturally attained social capital and indigenous resources as a thrust to address their problems (Kang'ethe, 2011). This will hopefully put them in the right developmental niche. Such discourses would also help correct some of the retrogressive services and nuances that these practitioners have been involved in making people to dwindle their confidence with them. Although it is important to analyse all the traditional practitioners, this researcher will give weight to traditional healers and traditional birth attendants. These, in his subjective perspective, are the ones apparently deemed to have more positive contribution to health issues than the rest.

\section{Methodology}

The article uses a systematic review of literature to elicit debate and discourse on the role and importance of traditional practitioners and the need to reposition, rejuvenate and reposition them to work within mainstream health and medical fraternity. The article has reviewed journals, books, United Nations publications etc.

\section{Operational Definition}

The word panacea which means an answer or a cure for all maladies is operationally taken to mean a satisfactory state of affairs; while the word perfidy that refers to the state of deception and trickery has been operationalized to mean an undesirable state of affairs. 


\section{The Panacea of Some Traditional Practitioners}

\subsection{They fill in medical gaps in many contexts, especially in rural areas}

Traditional practitioners such as the healers have been useful in the lives of people especially in yester years and are still significantly important in the rural areas, especially with poor health infrastructure (WHO, 2002; Setswe 1999; King et al, 1992). Healers are for instance many compared to modern doctors. For example as early as in 1995, there were 200,000 traditional healers practising in South Africa, compared to 25,000 modern doctors (Setswe, 1999; Kale, 1995). This means that the traditional healers: client ratio by far outdoes that of biomedical doctors: client one. According to Richter (2004), the ratio of traditional doctors to the general population in the Sub-Saharan Africa is approximately 1: 500 , while biomedical doctors' one is 1: 40,000 . It therefore means that there is no much congestion for clients to see a traditional healer, while accessing a doctor in many resource constrained countries is both an arduous and an uphill task (WHO, 2002). The healers are also very versatile. Where they operate, they are community counsellors, circumcisers, advisors, health practitioners, diviners, home builders, rain makers, advisors of political leaders, and they have also earned themselves the position of grassroots community leaders. It is this researcher's contention that their services should be professionalized and their consultation certificates are recognized by employers, the same way medical cards are used to justify the absence of workers in the workplace (Mbatha, et al, 2012). On a positive note, this kind of recognition and acceptance of their services in the modern world is however growing with time. In Botswana, for instance, the healers are usually recognized by the government. They are always invited to deliberate upon development issues alongside other civic leaders in the community. In the HIVIAIDS campaign in Botswana a representative of the traditional healers is always invited to sit in the country's highest HIVIAIDS organ, NACA charged with the responsibility of managing and driving the HIVIAIDS campaign in the country (NACA, 2009).

Perhaps the role and niche of these traditional practitioners is given credence due to the fact of their proximity to people, being culturally appropriate and people friendly. These are the first people that ailing people contact for their medication, hope, counselling and settling socially related problems such as poverty, death of livestock, etc (UNAIDS, 2000; King et al, 1992). Although today even people residing in urban areas seek their services, they are pivotally important in areas lagging behind in development, urbanization and civilization (Afoloyan, 2004). Their role is becoming more invaluable when they advance in technology, education, and hygiene. For those who have accommodated and collaborated with other players in the medical fraternity, their role has not only become more effective, but the phenomenon has also raised their professional demand (Kang'ethe, 2012). Infact in some countries such as Kenya, many qualified doctors have become herbalists and are working as traditional doctors. This has made the medical trade more scientific defeating the myth that traditional healers' medication lacks scientific validation (Mburu, 1983; Kang'ethe, 2009). It's good to make an examination of these practitioners with the objective of shedding light on their value, potency and relevance to their societies today.

\subsection{Traditional healers working in tandem with medical practitioners}

Just like the case of modern biomedical practitioners, traditional healers apply their art and diagnostic skills to arrive at the disease aetiology. This means diagnosing and arriving at who or what caused the disease, and why a particular individual was the target (King et al, 1992). The art of diagnosis constitute observation, exchange of information, probing by the healer, self reporting by the patient, and also divination. Divination is usually achieved by spiritual interpretation through divination objects such as boards, bones etc, dreams and visions (Mbuya, 2000). Although there has been ideological and attitudinal differences between biomedical personnel and the healers, resulting in bad blood between the two (Kang'ethe, 2012; UNAIDS, 2000), the healers of today are increasingly changing their perceptions and goals posts in order to be part of the medical solution to their countries health challenges in line with their governments' health guidelines. For example in South Africa, many healers have collaborated with medical fraternity teams in the HIVIAIDS campaign. Since 1980, for example, some of them volunteered to be part of the community health workers (CHWs) or community Based Health Education (CBHE) programmes. This has seen some of them being trained by the NGOs and government organs in order to adequately serve the communities. This has made them to be involved in activities such as TB control, dispensing of oral dehydration fluid, giving warning to communities against the re-use of razor blades, and dispensing of condoms. To this end, AIDS Foundation of South Africa has offered educational programmes to traditional healers. This is to ensure that their services are in compatible with national ethical guidelines and regulations (AIDS Foundation, 2012). 
In Botswana, the rigidity of the traditional healers is gradually waning, with some of them accepting to be part of the referral system especially for clients with HIVIAIDS symptoms. This has been a big breakthrough in the involvement of traditional healers in the HIVIAIDS campaign. This has laid to rest the situation in which the traditional healers were accused of peddling lies and mistruths about having the skills to handle and cure HIVIAIDS ( Kang'ethe, 2012).

\subsection{Traditional healers' healing process}

Because of this researcher's contention that the services of the traditional healers are important and need to be reconsidered, rejuvenated and placed in their rightful niche, it is good to go deep and analyze the actual services of the healers. They offer preventive and prophylactic services, treat different ailments and offer various medications to destroy the power of the clients' enemy (UNAIDS, 2000; Kang'ethe, 2009, 2012). In preventive work, the healers endeavour to protect the patient from possible afflictions. The healer can perform some ritualistic acts, for example advice the patient to wear totemic objects. The totemic objects, for example are believed to chase the evil spirits sent by the enemies. Subjective information on the ground suggests that among the people who access healers' services in Botswana, they take their newly born children for treatment and have them also given the totemic objects to wear them around their waists. It's no wonder today that many people from urban areas that believe and seek protection from the healers to have their new vehicles treated so that they may not get accidents. Some protection is also achieved by having the healer visit their clients' home usually at night to sprinkle some medication around the home (UNAIDS, 2000). In the same vein, among the Batswana who believe in the healer or ngaka ya setso, the meat to be used during the ceremonies such as wedding is usually treated in a secluded private room by the healer. This researcher bore evidence in one of the wedding ceremonies when, by default, he evidenced the traditional healer treating the meat for the ceremony. Upon the bull to secure meat for the ceremony being killed by the bullet, it was the traditional healer who was the first one to run and hold it by the tail. This, the researcher learnt was part of the ritualistic process to integrate the powers of the spirits of the ancestors into the ceremony as the healer repeatedly echoed "tima molelo" which means putting off the fire.

Perhaps the most common and uncomplicated task is the treatment for ailments. This involves the healer preparing different medical concoctions that are either taken orally, in powder form, and having poultices and lotions rubbed in the body. Treatment also takes the form of scarification, bloodletting and cupping as surgical procedures. The letting of the blood serve to cast out the illness. If the patient is believed to be bewitched, this treatment can take several forms such as performing various rituals to cast out the spell, induction of vomiting, bloodletting, whistling and calling upon the spirits of the ancestors for an answer (UNAIDS, 2000). The third type of service includes application of medications to destroy the power in others, usually the enemy of the patient/client. For example, one can be given some medications to put in the path of the enemy so that upon the enemy passing there, he/she can contract a fatal disease. This researcher will agree that some of these services especially in absence of developed modern medical facilities and infrastructure are desirable, while some would need some modifications, or abandonment altogether. It is therefore critical that these services are subjected to an examination to seek their rejuvenation, reclamation, repositioning and placing them in their rightful niche in the continuum of medical fraternity.

\subsection{Invaluable tasks of traditional birth attendants in some African countries}

Traditional birth attendants are practitioners who have been very important in maintaining the livelihood of communities through facilitating child delivery (Anderson \& Staugard, 1986; Abdool Karim et al, 1994). They are usually elderly women who may have been trained midwives for many years, or who have had culturally grounded intuitive skill to facilitate child delivery. For those who may not have trained in midwifery, they learn as apprentice under a skilled birth attendant. The apprenticeship may depend on the apprentice's capacity to learn. The traditional birth attendants have myriad tasks that make them professionally effective. They teach the pregnant women the behaviours they should avoid while pregnant, ritual bathing of the mother, disposal of the placenta after birth, application of healing medicine, and doing traditional massage after the mother delivery ( Anderson \& Staugard, 1986). Perhaps this is the only trade that usually does not attract payment. This is probably because a child is itself taken as a big blessing not only to the mother, but to the whole society. However, many relatives of the mother giving birth usually present smaller donations (Anderson \& Staugard, 1986).

However, despite the fact that the traditional birth attendants' niche has been changing goals posts as the modern maternity services increase, they are still very important in many countries of Africa, especially those with a large rural population. Although the situation is changing in South Africa as health infrastructure improves, in 1994, statistics in South Africa indicated that $60 \%$ of all the babies were born through the facilitation of traditional birth attendants (Abdool 
Karim et al, 1994). In DRC, for example, the place and role of traditional birth attendants is still important. This is because due to decades of war, most people live in rural areas with poor medical infrastructure (Matendo et al, 2011)

This researcher, therefore, is of the contention that it is unfair to discard the role of traditional practitioners such as TBA because of the advent of modern maternity services. He believes that since most of the TBA have the skills and ample knowledge, they should be incorporated and deployed to help the modern midwives. Since the process of integration is not adequately conceptualized, this researcher contends that the role of TBA to complement and supplement the role of modern midwives should be reconceptualised, reconsidered, rejuvenated and correctly and professionally repositioned.

\subsection{Collaborating TBA practitioners with modern midwives}

With myriad problems such as inadequate midwives and doctors to offer midwifery services, several African countries need to recognize the services of the TBA to supplement and compliment the child delivery services. This also finds support in the literature that indicates the impact of TBA in reducing child mortality and morbidity in countries such as Malawi (Bisika, 2008). Further experience on the ground also indicates that even countries with a better health infrastructure show gaps that the TBA can fill. For example although empirical information suggests that $85 \%$ of the population is within a $15 \mathrm{Km}$ radius and $76 \%$ within a walking distance (MOH/NACP41, 1998; Kang'ethe, 2008), a snapshot examination of Marina National Referral Hospital, the biggest in the country reveals inadequate space beds for women needing midwifery services. This scenario indicates that in other countries with glaring health challenges and infrastructure, the situation could be worse. It is therefore recommendable that TBA in the villages be retrained and given some facilities that they could continue executing midwifery services from their homes (Bisika, 2008). Perhaps a worrying state of affairs in countries such as Botswana is the mortality rate that children in the hands of modern midwives experiences with some scholars indicating that the nursing profession in Botswana lacks or is weak in midwifery component. This strengthens the need to bolster child delivery services with the services of the TBA at their homes. Perhaps also the scenario of strengthening TBA to work from their homes parallels the institutionalization in Botswana of 1996 of community home based care community in order to decongest the sick people in hospitals (Munodawafa, 1998). It is also important to note that effective repositioning, rejuvenating and fully integrating them into the modern child delivery process requires government goodwill alongside some legislation.

In Kenya, the services of the TBA especially in very rural areas have been integrated and recognized by the government. The TBA have been equipped with adequate knowledge to hygienically effectuate delivery. The TBA are given delivery kits with all the tools required to effect delivery. They have been doing a sterlingly important role especially in the rural areas (African Population and Health Research Centre et al, 2008). Perhaps this is why this researcher advocates and lobbies for their position and niche to be reconceptualised, reconsidered. People's attitudes should undergo a paradigm shift if the success in repositioning, rejuvenating and integrating these practitioners with the modern bio medics is to be achieved. Pivotally, the professionalization of their services should not be overemphasized.

\section{The Perfidy of some Traditional Practitioners}

With modernization, eurocentrism, civilization and globalization taking deep toll, the role, value, importance and niche of the traditional practitioners are gradually waning away. The continuum of waning away, however, depends on the type of the society in context, with people from largely rural areas still upholding immense dignity of these practitioners (Mburu, 1993; King et al, 1992). However, it is pertinent to consider the retrogressive aspects associated with these traditional practitioners. This is with the hope of correcting their flaws and also helps the government policy makers to position themselves in the event of effectuating a fruitful collaboration and integration of these practitioners.

\subsection{Negatively perceived roles of healers, Sangomas, wizards and witches}

Generally, this group of the practitioners is believed to have powers of interfering with the spiritual world to negatively affect the enemies of their clients. This means negatively affecting the health, wealth and happiness of those who did bad things to their clients. In some cases, literature indicates that these practitioners could cause death of their clients' enemies, or their children (Mbuya, 2000). This means that while the client may be celebrating, the victim will be mourning. The retrogressive aspects of these practitioners are that the victim could also be using other practitioners to continue launching harmful onslaught. Therefore, both clients would also become the victims of one another, and none will be the victor. This also creates a culture of related crimes as each party may use other unorthodox mechanism to hit at one 
another (Petrus, 2010). Perhaps this is why these practitioners are viewed in many parts of the world practising witchcraft as practitioners out to cause enmity, sadness and frustrations among societal members (Petrus, 2010). In many Southern Africa communities practising witchcraft, even the police have not succeeded in handling witchcraft related crimes. This is why Petrus (2010) calls for more education regarding witchcraft to as many different stakeholders as possible in South Africa (De Lange, 2012).

Today, although some of these practitioners such as the healers and the TBA are still recognized and respected in some countries such as Botswana and South Africa, it is usually not so in some countries where they are increasingly being threatened by death (Masha, 2013). In recent years in Kenya, for instance, once an individual is suspected of practising witchcraft, he/she is usually burnt with all the paraphernalia that he/she uses for trade. More often, his/her family members are usually banished from the area and if they have to remain back, they must be exorcised or cleansed.

This is because of the sins that they or their parents had delved in. In early this year, 2013, Police and officers from the Provincial Administration in Kilifi County of Kenya revealed that at least 20 individuals suspected of engaging in witchcraft get killed every month (Masha 2013). Although such deaths takes away their cultural rights as well as their human rights embedded in many countries' bill of rights (Barrett-Grant, Fine, Heywood \& Strode, 2001; Kang'ethe, 2013), this shows societal change in goal posts towards the place and value of these practitioners.

Perhaps the practice of many African traditional religions (ATR) that appears to be a mixed breed of the current Christian values with traditionalism and culturalism has been a response to accommodate modernization while still allowing traditionalism to thrive. Such religions include ZCC (Zion Church of Christ), AIPCA (African Independent Pentecostal Church of Africa) in both Botswana and South Africa. In these churches, they can consult across the divide of modern religious values as well as traditional values (Kang'ethe \& Gaseitsiwe, 2012).

\section{The Way Foward/Recommendations}

It is this researcher's contention that perceptibly, some traditional practitioners such as traditional birth attendants, healers and herbalists have had a pivotal role to play in the lives of people especially in countries whose health infrastructure is still growing at a lagged out process (UNAIDS, 2000). This is supported by the WHO (2002) sentiments that Africa needs these traditional practitioners because of the dearth of medical and health infrastructure. However, a mixed breed between their roles and modern bio medics needs to be struck. Some aspects of these traditional practitioners such as Sangomas, witches and wizards are viewed in some countries such as Kenya as practitioners who should be annihilated altogether. To the contrary, they are viewed as important practitioners in some countries such as Botswana and South Africa. In Botswana and South Africa, for instance, their values can be ascertained by the fact that even people are named after practitioners' trade. For example, the name "Moloi" (a witch) is a commonly acceptable name in these two countries, but mostly in Botswana.

It is also this researcher's contention that the countries need to make an examination of the pros and cons of these practitioners with a view of expediting collaboration and integration between traditional and modern practitioners in their countries' health and medical fraternity. This researcher considers it critically unfair to wish away the role of some of these practitioners especially in African countries where modern health and medical facilities are still not adequately developed. With congestion in the medical and health facilities due to the increase in diseases such as HIVIAIDS, inadequate beds and weak human resource to effect birth delivery in some settings, with inadequate number of health staff responsible for psychosocial support such as counselling in many African countries such as Botswana and South Africa, the role of TBA, healers and spiritualists are poignantly important (Kang'ethe, 2009; Mbuya ,2000).

This researcher also considers it pertinent that these traditional practitioners are flexible to accommodative new technologies, ideologies, and accept to work in tandem with other professionals in the field such as biomedical practitioners. They should accept training and adopt new strategies to face contemporary health demands adequately. They should also relax their versatile approach to the problems they handle and specialise so that they may have a room to grow and to be effective in their trade. Otherwise, a healer who is for example a herbalist, a diviner, a rainmaker is bound to scatter his/her professionalism with the result of being a master of none. Allowing specialization would also allow their clients to know who is who for the problem they may be facing.

Diverse researchers in some countries are of the view that governments should pass a bill that will provide for the formation of traditional healers council to oversee the registration and regulation of the practice of the traditional practitioners. This is due to some critical gaps that have empirically been validated within their practice. In Botswana, for example, the 2008 research participants in Tsabong district expressed the need to have the Bongaka Association that was launched way back in 1993 (to register and regulate the work of the traditional healers), to be proactive to licence the healers and enforce accountability in case of their professional flaws ( Kang'ethe, 2012; Bonepwa Team, 2008). 
It is also important that the individuals accessing the services of traditional practitioners be aware of their rights and if violated seek legal redress. The case of many healers advising people to stop taking ARVs resulting in them becoming weaker or face death easily could be taken up by the clients themselves or their relatives. The healers need to be accountable.

\section{Conclusion}

This researcher, an advocate of indigenization considers it pertinent to reconsider, rejuvenate, integrate and reposition the services of most of the traditional practitioners such as the healers and traditional birth attendants. He feels that Africans have unfairly discarded and demeaned the role of their skilled traditional practitioners whose role is apparently critical as modern health infrastructure shows glaring gaps begging to be filled. These practitioners need not only professional recognition, but policy and resource support so that their professional niche can be adequately and professionally established. Professional collaboration of some of these practitioners with modern biomedical practitioners is critical, topical and long overdue.

\section{References}

Abdool, Karim, S.S, Ziqubu-Page, T.T, Arendse, R. (1994). Bridging the gap: Potential for a health care partnership between African Traditional healers and biomedical personnel in South Africa. Project Report prepared prepared for the South African Medical Research Council. South African Medical Journal, 84 (December, Supplement):1-16

Afolayan, F. (2004). Culture and customs of South Africa. Westport, Connecticut, London. Greenwood Press.

African Population and Health Research Centre et al. (2008). The persistence and challenges of homebirths: perspectives of traditional birth attendants in urban Kenya. Vol. 24(1) 36-45.

AIDS Foundation of South Africa (2012). Traditional Medicine, culture and health. Hyyp://www.aids.org.za/page/traditional-medicineculture-and health (accessed 15th January 2012.

Anderson, S., Staugard, F. (1986). Traditional Midwives. Traditional Medicine in Botswana. Gaborone. Ipelegeng Publishers

Bisika, T. (2008). The effectiveness of the TBA programme in reducing maternal mortality and morbidity in Malawi. East African Journal of Public Health. 2008; 5(2):103-110

De Lange, I. (2012). Witchcraft education needed. The citizen. $6^{\text {th }}$ July 2012.

Kale, R. (1995) South Africa's Health: Traditional healers in South Africa: A parallel health care system. British Medical Journal, 310 (6 May): 1182-1185.

Kang'ethe, S.M. (2009). Traditional healers as caregivers to HIVIAID clients and other terminally challenged persons in Kanye community home-based care programme (CHBC), Botswana. Sahara Journal. Vol. 6 (2). September 2009. Pp.83-91.

Kang'ethe, S.M (2011). Evidences of indigenous knowledge systems driving care giving in care programmes in Botswana. Fort Hare Papers. Vol 18, 2011. Pp 5-15.

Kang'ethe, S.M (2012). Attitudes of PLWA and other selected communities in Tsabong towards operationalizing bio medical and traditional therapies in tandem to face the AIDs epidemic. Social Work/Maatskaplike, 2012.46 (1). PP 55-69.

Kang'ethe, S.M. (2013). The panacea and perfidy of cultural rites of circumcision in African countries: Examples from Kenya, Botswana and South Africa. EASSRR Journal. Vol. xxix, No 1, pp. 107-123.

Kang'ethe, S. M. \& Gaseitsiwe, B. (2011). Religious Education for Form Three. Gaborone. Botsalano Publishers.

Kang'ethe, S. M \& Rhakudu, M. (2010). Religious Education book for form Two. Gaborone. Heinemann Publisher

King, R., Homsy, J., Allen, S. (1992). Traditional medicine vs modern medicine for AIDS. VIII International Conference on AIDS. Amsterdam, July (abstract Pob 3394).

Masha, J. (2013). At least 20 elderly people killed monthly in Kilifi over witchcraft allegations-Report. Standard Newspaper. $4^{\text {th }}$ July 2013.

Matendo, R. et al. (2011).Reduced perinatal mortality following enhanced training of birth attendants in the Democratic Republic of Congo: a time-dependent effect. BMC Medicine 2011, 9:93 doi:10.1186/1741-7015-9-93.

Mbatha N, Street RA, Ngcobo M, Gqaleni 2012. Sick certificates issues by South African traditional health practitioners: Current legislation, challenges and the way Forward. S Afr Med J 2012: 102: 129-131.

Mburu, F.M. (1983). Professionalization and differentiation of traditional medicine in Kenya. International African Institute conference on the professionalization of African Medicine, Gaborone, Botswana.

Mbuya, J. C .(2000). The AIDS Epidemic in South Africa. Johannesburg, Henco Design.

National AIDS Coordinating Agency (NACA) 2009. 'Ministry of State President, Government of Botswana,' The Second National Strategic Framework for HIV and AIDS: 2010-2016

Petrus, T. (2010). Defining witchcraft related crime in the Eastern Cape Province of South Africa. International Journal of Sociology and Anthropology. Vol 3(1). Pp 1-8 January 2011.

Richter, M.L. (2004). Traditional healing and humanrights in South Africa. XV International AIDS Conference, Bangkok, 11-16 July (Abstractno: MoPeE4200).

Setswe, G. (1999). The role of Traditional healers and Primary Health care in South Africa. Health SA Gesondheld, 4(2):56-60 
UNAIDS (2000). Collaboration with traditional healers in HIVIAIDS prevention and care in Sub -Saharan Africa. A literature Review, Geneva, Switzerland.

WHO. (2002). Community Home-Based Care in Resource-Limited Settings. A Framework for Action. Switzerland. 